PRZEGLĄD NAUK HISTORYCZNYCH 2020, R. XIX, NR 1

http://dx.doi.org/10.18778/1644-857X.19.01.12

\title{
Wpływ myśli Jerzego Maternickiego na współczesną historiografię ukraińską
}

Streszczenie. W artykule przedstawiono wpływ prac Jerzego Maternickiego na rozwój współczesnej historiografii ukraińskiej. Autorka dokonała analizy szeregu prac historyków ukraińskich, którzy powołuja się w swoich badaniach na jego opracowania. Wykazała istotny wpływ Jerzego Maternickiego na umacnianie polsko-ukraińskich kontaktów naukowych.

Słowa kluczowe: Jerzy Wiktor Maternicki, polska historiografia, współczesna historiografia ukraińska, Uniwersytet Warszawski, Uniwersytet Rzeszowski.

pośród najbardziej znanych polskich historyków historiografii Jerzy Wiktor Maternicki jest najczęściej cytowany przez ukraińskich badaczy. Ci ostatni cenia zwłaszcza jego prace poświęcone dziejom polskiej nauki historycznej XIX i XX w. oraz problemom nauczania historii w szkołach średnich i wyższych, jak również jego aktywną działalność na polu organizacji i popularyzacji nauki. Problem wpływu myśli J. Maternickiego na współczesną historiografię ukraińską nie był jeszcze przedmiotem badań. Celem artykułu jest zatem analiza sposobu postrzegania i interpretacji poglądów polskiego historyka przez współczesnych badaczy ukraińskich. W tekście zajęto się przede wszystkim oddziaływaniem na historiografię ukraińska prac J. Maternickiego z zakresu historii historiografii oraz metodologii historii. Wielu współczesnych historyków polskich (w tym sam Jerzy Maternicki, Andrzej

*Wydział Historyczny, Katedra Historii Ukrainy, e-mail: bohdashyna@gmail.com 
Stępnik, Anna Czerniecka-Haberko) drukuje swoje artykuły w czasopismach ukraińskich, w których to opracowaniach popularyzowane sa poglady tego znanego historyka historiografii. Prace te sa pośrednio związane $z$ tematyka artykułu, ponieważ wpisują się w kontekst tego, co można określić mianem najnowszej historiografii ukraińskiej.

Zacznijmy zatem od przypomnienia kilku faktów $z$ biografii i twórczości słynnego naukowca. Po ukończeniu Wydziału Historycznego Uniwersytetu Warszawskiego (1958) młody badacz ukończył tamże studia doktoranckie (1966) i obronił rozprawę doktorska przygotowana pod kierunkiem Wandy Moszczeńskiej (1971). W swojej Alma Mater Jerzy Wiktor Maternicki przeszedł drogę od wykładowcy do profesora: był asystentem i starszym asystentem (1959-1966), adiunktem (1967-1971), docentem (1971-1978), profesorem nadzwyczajnym (1978-1988) i profesorem zwyczajnym (1988-1997). Pełnił funkcje prodziekana Wydziału Historycznego (1976-1978) i kierownika Zakładu Historii Historiografii i Dydaktyki Historii (1976-1997). Jednocześnie był kierownikiem Studium Podyplomowego Historii (1970-1985) oraz przewodniczacym Międzyuczelnianego Zespołu Historii Historiografii i Dydaktyki Historii (1988-1992). W latach 1993-2001 J. Maternicki był kierownikiem Zakładu Historii Historiografii i Metodologii Historii Wyższej Szkoły Pedagogicznej w Rzeszowie, a od 2001 r. - kierownikiem Zakładu Historii Historiografii i Metodologii Historii Uniwersytetu Rzeszowskiego.

Jerzy Maternicki jest autorem ponad 500 prac naukowych, w tym 22 książek poświęconych historiografii polskiej XIX i XX w., edukacji, świadomości i kulturze historycznej Polaków w XVIIIXX w. oraz dydaktyce historii. Profesor kierował także ogólnopolskimi projektami badawczymi. W latach 1983-1990 był to projekt pt. Polskie środowisko historyczne 1918-1939, a w latach 1988-1990 Tradycja grunwaldzka. Wyniki tych badań zostały opublikowane w pracach zbiorowych, monografiach i licznych artykułach. Szczególne znaczenie dla ukraińskiej historiografii miał pierwszy $z$ tych projektów, ponieważ wiele uwagi poświęcono tu historykom lwowskim $z$ okresu międzywojennego. Nowe fakty i oceny zintensyfikowały badania na tym polu nie tylko w Polsce, lecz także na Ukrainie.

W latach 2002-2007 J. Maternicki był przewodniczącym (później jednym ze współprzewodniczących) międzynarodowego pro- 
jektu badawczego pt. Wielokulturowe środowisko historyczne Lwowa $w$ XIX i XX w., a od 2007 r. współprzewodniczącym polsko-ukraińskiego projektu pt. Historia - mentalność - tożsamość. Miejsce $i$ rola historii oraz historyków $w$ życiu narodu polskiego i ukraińskiego. W ramach wspomnianego tu pierwszego projektu zespół ukraińskich, polskich i niemieckich historyków pracujacych pod kierunkiem J. Maternickiego i Leonida Zaszkilniaka organizował coroczne konferencje sprawozdawcze. Po każdej z nich publikowano monografie wieloautorskie (łącznie wydano ich pięć) ${ }^{1}$. Akordem końcowym owocnej współpracy ukraińskich i polskich naukowców było dwutomowe wydawnictwo poświęcone wybitnym historykom lwowskim XIX i XX w. ${ }^{2}$

Po zrealizowaniu tego projektu badawczego współpraca historyków ukraińskich i polskich była kontynuowana. W 2007 r. w Rzeszowie został powołany do życia zespól, który podjął pracę nad projektem pt. Historia - mentalność - tożsamość. Miejsce i rola historii oraz historyków $w$ życiu narodu polskiego i ukraińskiego $w$ XIX i XX wieku. Współprzewodniczacymi tego zespołu byli J. Maternicki i L. Zaszkilniak, a wśród uczestników znaleźli się profesorowie Włodzimierz Bonusiak (Rzeszów), Wojciech Wrzosek (Poznań), Rafał Stobiecki (Łódź), Andrzej Stępnik (Lublin), Witalij Telwak (Drohobycz) oraz doktorzy Joanna Pisulińska (Rzeszów) i Paweł Sierżęga (Rzeszów). Rezultatem działań tego zespołu było zorganizowanie kilku międzynarodowych konferencji pod wspólnym tytułem Historia - mentalność - tożsamość. Po każdej z nich wydawano publikacje pokonferencyjne ${ }^{3}$. We wrześniu 2011 r. J. Maternicki

1 Wielokulturowe środowisko historyczne Lwowa w XIX i XX w., t. I, red. J. Maternicki, L. Zaszkilniak, Rzeszów 2004; Wielokulturowe środowisko historyczne Lwowa w XX i XIX w., t. II, red. J. Maternicki, L. Zaszkilniak, Rzeszów 2005; Wielokulturowe środowisko historyczne Lwowa w XX i XIX w., t. III, red. J. Maternicki, L. Zaszkilniak, Rzeszów 2005; Wielokulturowe środowisko historyczne Lwowa w XX $i$ XIX w., t. IV, red. J. Maternicki, L. Zaszkilniak, Lwów-Rzeszów 2006; Wielokulturowe środowisko historyczne Lwowa $w X X i X I X w .$, t. V, red. J. Maternicki, L. Zaszkilniak, Rzeszów 2007.

2 Złota ksiegga historiografii lwowskiej XIX i XX wieku, red. J. Maternicki, L. Zaszkilniak, Rzeszów 2007; Złota księga historiografii lwowskiej XIX i XX wieku, t. II, red. J. Maternicki, P. Sierżęga, L. Zaszkilniak, Rzeszów 2014.

${ }^{3}$ Historia-mentalność- tożsamość. Miejsce i rola historii oraz historyków $w \dot{z} y$ ciu narodu polskiego i ukrainskiego $w$ XIX $i$ XX wieku, red. J. Pisulińska, P. Sierżęga, L. Zaszkilniak, wstęp J. Maternicki, Rzeszów 2008; Historia-mentalność - tożsamość: studia $z$ historii, historii historiografii i metodologii historii, red. K. Polasik-Wrzosek, W. Wrzosek, L. Zaszkilniak, Poznań 2010; Istorija-mentalnist' - identicznist', t. IV (Istoryczna pam'jat' ukraijnnciw i poljakiw u period formuwannja 
został wybrany pierwszym prezesem Polskiego Towarzystwa Historiograficznego. Uczestniczył również w realizacji ukraińsko-polsko-austriackiego projektu pt. Galicja 1772-1918. Miał też swój udział w przygotowaniu do druku trzytomowej publikacji pt. Galicja 1772-1918. Problemy metodologiczne, stan i potrzeby badań ${ }^{4}$.

Organizowane przez J. Maternickiego konferencje i wydawane przez niego prace zostały dostrzeżone przez ukraińskie środowisko historyczne. W tamtejszych czasopismach ukazywały się liczne sprawozdania $z$ sympozjów i recenzje $z$ tomów pokonferencyjnych ${ }^{5}$. $\mathrm{Na}$ szczególna uwage i osobne odnotowanie zasługuje natomiast obszerna recenzja książki J. Maternickiego pt. Historia $i \dot{z} y c i e$ narodu. Poglady i postawy historyków polskich XIX i XX w. (Rzeszów 2009, ss. 490), przygotowana przez Lidię Łazurko ${ }^{6}$. Rzecz jasna, wpływ twórczości J. Maternickiego na rozwój współczesnej historiografii ukraińskiej historiografii jest znacznie większy. Najczęściej odwołują się do jego prac ukraińscy autorzy, którzy podejmuja badania nad historiografia XIX i XX stulecia. Sa to m.in. Olena Arkusza i Marian Mudry, Olena Bohdaszyna, Leonid Zaszkilniak, Lidia Łazurko, Witalij Telwak, Oksana Ruda oraz Eugeniusz Sinkiewicz.

Jerzy Maternicki powiązał moment powstania nowoczesnej historiografii polskiej $z$ początkiem dominacji myśli pozytywistycznej $\mathrm{w}$ latach sześćdziesiątych XIX w. ${ }^{7}$ Podobnie wyglądała

istorycznoji swidimosti $w$ XIX - perszij połowyni XX stolittja), red. L. Zaszkilniak, J. Pisulińska, P. Sierżęga, Lwiw 2011; Historia, mentalność, tożsamość: Rosja i Europa Zachodnia w polskiej i ukrainskiej historiografii XIX I XX wieku, red. E. Koko, M. Nowak, L. Zaszkilniak, Gdańsk 2013.

4 Galicja 1772-1918. Problemy metodologiczne, stan i potrzeby badañ, t. I-III, red. A. Kawalec, W. Wierzbieniec, L. Zaszkilniak, wstęp J. Maternicki, Rzeszów 2011.

${ }^{5}$ L.O. Zaszkilniak, II Miżnarodna konferencija „Istorija - mentalnist' - identycznist”, „Ukraijns'kyj istorycznyj źurnał” 2004, nr 1, s. 232-233; L.O. Z a s zki1niak, M.M. Kril, Tretja miżnarodna naukowa konferencyja „Bahatokulturne istoryczne seredowiszcze Lwiwa u XIX-XX st., „Ukraijns'kyj istorycznyj źurnał” 2005, nr 2, s. 224-226; L.O. Za szkilniak, O.W. Ru d a, IV Miżnarodna naukowa konferencija „Bahatokulturnyje istoryczne seredowiszcze Lwiwa $w$ XIX - perszij połowyni XX st.”, „Ukraijns'kyj istorycznyj źurnał” 2006, nr 1, s. 231-233; W.W. Telwak, W.P. Pedycz, III Miżnarodna konferencyja "Istorija - mentalnist' - identicznist”, „Ukraijns'kyj istorycznyj źurnał” 2009, nr 6, s. 225-226.

${ }^{6}$ L. Łazurko, Istorija i żyttja narodu $w$ wiziji Jeży Maternickoho, „Dorohobyc'kyj krajeznawczyj zbirnyk" 2011, z. 14-15, s. 634-644.

7 J. Maternicki, Historia i życie narodu: poglady i postawy historyków polskich XIX i XX w., Rzeszów 2009, s. 231, 270-271, 369-371. 
sytuacja historiografii ukraińskiej ${ }^{8}$, jak też wielu innych historiografii europejskich. Zdaniem J. Maternickiego w latach 1900-1918 w historiografii polskiej uwidoczniły się wpływy neoromantyzmu i modernizmu, aczkolwiek w okresie od 1908 do 1914 r. nastapił częściowy powrót do tradycji pozytywistycznej9.

Oksana Ruda akceptuje wyróżnione przez J. Maternickiego trzy podokresy dominacji koncepcji neoromantycznych w historiografii polskiej. Pierwszy (1900-1906/1907) charakteryzował się wciąż znaczacym wpływem pozytywizmu, krytyczna metoda badawczą i przestrzeganiem pozytywistycznych zasad metodologicznych. W drugim podokresie (1908-1914) aspekt naukowo-krytyczny został podporządkowany aspektowi polityczno-ideologicznemu. Trzeci podokres (1914-1918) wiązał się $z$ kolei odejściem od idealizacji przeszłości i powrotem do krytycznej analizy. Przełomowymi momentami tych etapów była rewolucja 1905 r. i początek pierwszej wojny światowej ${ }^{10}$.

W swoich licznych publikacjach J. Maternicki dokładnie analizuje prace wielu znanych polskich badaczy, dokonujac oceny ich pogląów teoretycznych i metodologicznych. Przykładowo napisał on kilka prac, w których zajął się omówieniem pozytywistycznych poglądów młodego Adama Szelagowskiego ${ }^{11}$. Lidia Łazurko uważa za słuszne stwierdzenie J. Maternickiego, który charakteryzuje

8 Por. O.N. Bohdaszyna, Pozitiwizm $w$ istoriczeskoj naukie na Ukrainie (60-e gg. XIX-20-e gg. XX ww.), Charkiw 2013.

9 J. Maternicki, Polska refleksja teoretyczna i metodologiczna $w$ dziedzinie historii w okresie modernizmu i neoromantyzmu. Metamorfozy myśli pozytywistycznej, [w:] id e m, Historiografia i kultura historyczna: studia $i$ szkice, t. I, Warszawa 1990, s. 220-272; id e m, Polskie środowisko historyczne w latach 1900-1918, „Przegląd Humanistyczny” 1980, nr 4-5, s. 11-29; id em, „Rewolucje” i przełomy $w$ historiografii polskiej XIX $i$ XX $w$. Próba analizy czynników sprawczych, [w:] idem, Kultura historyczna dawna i współczesna: Studia i szkice, Warszawa 1979 , s. $11-31$.

10 J. Maternicki, Idee i postawy. Historia i historycy polscy 1914-1918. Studium historiograficzne, Warszawa 1975, s. 19; O. Ruda, Berestejska unija u doslidżennjach lwiws'kich istorykiw (1890-1914), „Problemy słow’janoznawstwa” 2008, z. 57, s. 64-65.

11 J. Maternicki, Adam Szelagowski i jego poglady na historie, „Przegląd Humanistyczny" 1989, nr 11, s. 123-153; nr 12, s. 105-137; ide m, Trudna profesura. Adam Szelagowski wśród przeciwieństw $i$ niepowodzeń życiowych we Lwowie w latach 1909-1939, [w:] i d e m, Historia i historycy: Studia i szkice historiograficzne, Rzeszów 2005, s. 174-204; id e m, Adam Szelagowski wobec historii socjologicznej, [w:] Wielokulturowe środowisko..., t. IV, s. 178-198; O.N. Bohdaszyna, op. cit., s. 41 i n. 
A. Szelagowskiego jako człowieka „ostrożnego, dalekiego od radykalizmu modernistę, który podkreślał potrzebę wzmocnienia związków socjologii i historii [...] oraz próbował eksponować badania społecznych i ekonomicznych procesów na tle szerokiego rozumienia kultury"12.

W dyskusji o przynależności Ludwika Kubali do warszawskiej czy krakowskiej szkoły naukowej Oksana Pestrykowa poparła pogląd J. Maternickiego o przynależności L. Kubali do szkoły warszawskiej ${ }^{13}$. Eugeniusz Sienkiewicz uważa za słuszną myś1 rzeszowskiego profesora podważającego dominujace przekonanie o zaakceptowaniu przez Stanisława Smolkę poglądu Józefa Szujskiego na temat unii polsko-litewskiej z 1569 r.: „w poglądach na [unię lubelska] S. Smolka wyraźnie stanął po stronie J. Szujskiego. Nie wydaje nam się, że ta myśl jest prawdziwa"14. Ten sam autor stwierdził, że J. Maternicki ma rację w kwestii przyczyn zmiany poglądów Michała Bobrzyńskiego na okoliczności zawarcia i następstwa unii jagiellońskiej ${ }^{15}$.

Eugeniusz Sienkiewicz powołując się na J. Maternickiego, uwa$\dot{z ̇ a}$, że jedną $z$ przyczyn kryzysu, w jakim pogrą̇̇ł się „Kwartalnik Historyczny” w okresie międzywojennym, było „wyraźne pogorszenie warunków materialnych"16. Pogląd ten podtrzymuje również L. Łazurko w swoich ukraińsko- i polskojęzycznych studiach o „Kwartalniku Historycznym” okresu międzywojennego, stale cytując prace J. Maternickiego o tym czasopiśmie. W szczególności badaczka ta zauważyła, że: „Jerzy Maternicki zdołał odszukać i zanalizować nieliczne publikacje "Kwartalnika" o charakterze me-

12 J. Maternicki, Adam Szelagowski wobec idei historii socjologicznej, [w:] i d e m, Historia i życie narodu..., s. 437; L. Łazu rko, Kwestie metodologiczne na łamach „Kwartalnika Historycznego” (do 1939 r.), „Klio Polska. Studia i Materiały z Dziejów Historiografi i Polskiej” 2016, t. VIII, s. 26.

${ }_{13}$ J. Maternicki, Historia i życie narodu..., s. 238; O. Pestrykowa, Doba Chmielnyczczyny w interpretaciji polskoho istoryka Ludwika Kubali, „Hrani” 2018, nr 2 (21) s. 85.

${ }^{14}$ J. Maternicki, Historiografia i kultura historyczna..., t. I, s. 135.

15 E.H. Sinkiewicz, Kozac'kyj i jagiełłons'kyj mify $w$ polskoj ta ukraijnskij istoriografiji, „Naukowi praci Mikołajiws'koho derżawnoho humanitarnoho uniwersytetu im. Petra Mohyły kompleksu Kijewo-Mohyljans'ka akademija”, Ser.: Istoryczni nauki 2008, t. XCVI, z. 83, s. 242.

${ }_{16}$ J. Maternicki, Historia $i$ historycy..., s. 26; E. Sinkiewicz, Zmina paradygmy polskoji istoriografiji $w$ umowach widrodżennja derżawnosti (1918-1939), „Naukowi praci Czornomor. derżw. un-t im. P. Mohyły”, Ser.: istorija 2011, t. CLIV, z. 142 , s. 89. 
todologicznym, szukając odpowiedzi na pytanie, w jakim stopniu czasopismo to inspirowało nowe kierunki badań historiograficznych" ${ }^{17}$. W całej rozciagłości zgadzamy się $z$ wysoka ocena L. Łazurko w odniesieniu do prac J. Maternickiego na temat "Kwartalnika Historycznego”. Rzeczywiście, powstanie tego czasopisma było logicznym następstwem rozwoju polskiej nauki historycznej w erze pozytywizmu ${ }^{18}$.

Według obliczeń Jerzego Maternickiego w drugiej połowie XIX i na początku XX w. we Lwowie zamieszkała największa grupa polskich historyków ${ }^{19}$. Jego zdaniem lwowscy naukowcy, w przeciwieństwie do warszawskich i krakowskich, nie zaproponowali własnej, oryginalnej koncepcji rozwoju historycznego Polski ${ }^{20}$. Maternicki doszedł jednak do wniosku, że poziom merytoryczny prac historyków polskich związanych ze Lwowem był bardzo wysoki. Zwrócił uwage na ich bardzo dobre przygotowanie do badania źródeł, co odpowiadało standardom badawczym epoki pozytywizmu ${ }^{21}$. Swój wniosek uzasadniał również tym, że czołowi polscy historycy ze Lwowa w latach 1865-1918 odebrali wykształcenie na uniwersytetach w Niemczech (Władysław Abraham, Oswald Balzer, Bronisław Dembiński, Wojciech Kętrzyński) oraz w Austrii (Ludwik Kubala, Antoni Prochaska, Tadeusz Wojciechowski) ${ }^{22}$.

Lidia Łazurko, Olena Arkusza i Marian Mudry popieraja dość dyskusyjne stwierdzenie J. Maternickiego, który wiąże fakt powstania w ostatniej tercji XIX w. silnego środowiska historiograficznego we Lwowie, przede wszystkim $z$ polonizacją Uniwersytetu Jana Kazimierza $^{23}$. Tymczasem sam J. Maternicki w innej swojej pracy

17 J. Maternicki, Adam Szelagowski wobec idei..., s. 437; L. Łazurko, Kwestie metodologiczne..., s. 26.

18 J. Maternicki, Miejsce i rola „Kwartalnika Historycznego”, [w:] id e m, Historia jako dialog. Studia i szkice historiograficzne, Rzeszów 1996, s. 279-280.

19 J. Maternicki, Miejsce i rola..., s. 279; idem, Historia i życie narodu..., s. 229; O.N. Bohdaszyna, op. cit., s. 41.

${ }^{20}$ J. Maternicki, Historia $i$ życie narodu..., s. 230; O.N. Bohdaszyna, op. cit., s. 41.

${ }^{21}$ J. Maternicki, Historia i życie narodu..., s. 231, 270-271, 369-371; O.N. Bohdaszyna, op. cit., s. 41.

${ }^{22}$ J. Maternicki, Historia i życie narodu..., s. 370-371; O.N. Bohdaszyna, op. cit., s. 41.

${ }^{23}$ J. Maternicki, Polskie szkoły historyczne we Lwowie w XIX w., [w:] Wielokulturowe środowisko historyczne..., t. III, s. 28 i n.; L. Łazurko, Spiwpracja redakciji czasopysu "Kwartalnik Historyczny” z Lwiws'kym uniwersytetom (1887-1914 rr.), [w:] Istorija ta istoryky u Lwiws'komu uniwersyteti: tradycii ta 
stwierdza, że czynnikami wpływającymi na powstanie w tym mieście silnego środowiska historycznego, oprócz tego, że mieszkało tu wielu polskich historyków, były też duże zbiory dokumentów i literatury w bibliotekach Uniwersytetu Lwowskiego, Zakładzie Narodowym im. Ossolińskich, jak również księgozbiorach Dzieduszyckich, Baworowskich, Pawlikowskich oraz w Archiwum Krajowym Aktów Grodzkich i Ziemskich ${ }^{24}$.

Najczęściej jednak ukraińscy uczeni po prostu akceptuja poglądy polskiego badacza. Przykładowo L. Zaszkilniak, powołując się na J. Maternickiego ${ }^{25}$, uważa za charakterystyczna cechę polskiej historiografii tego czasu „wzmocnienie związu historii z polityką: argumenty historyczne zamieniły się w postulaty ideologii politycznej, a ta $z$ kolei tworzyła przydatna wizję historii narodowej"26. Lidia Łazurko w pełni zgadza się $z$ teza polskiego uczonego, który twierdzi, że powstanie „Kwartalnika Historycznego” było logiczna konsekwencja rozwoju polskiej nauki historycznej i tych wszystkich zmian, które zaszły na ziemiach zamieszkałych przez Polaków w epoce pozytywizmu ${ }^{27}$.

W ksiażce pt. Historyczne obrazy „sasiadów” na pograniczu ukraińsko-polsko-białoruskim: mity - studia - pamięć (2018) podano za J. Maternickim definicję pojęcia mitu: „Pod pojęciem mitu historycznego rozumiemy te mityczne wyobrażenia, jakie przynajmniej $z$ "zewnętrznej" strony narracji odnosza się do pewnych zjawisk historycznych, potwierdzonych (przez historyków) za pomoca źródeł, wydarzeń, postaci, instytucji. [...] Mit historyczny jest opowiadaniem pewnych wartości, aspiracji i nadziei, który nie tyle mówi o tym, co było, ile o tym, jak miało się stać”. Autorzy tej książki $\mathrm{w}$ pełni aprobuja takie rozumienie tego pojęcia ${ }^{28}$.

suczasnist'. Do 75-littja stworennja istorycznoho fakultetu, red. L. Zaszkilniak, P. Serżenga, Lwiw 2015, s. 185; O. Arku s za, M. Myd ryj, Istoryczni doslidżennja $w$ intelektualnych ta politycznych kontekstach pidawstrijs'koji Hałyczyny, „Wisnyk Lwiws'koho uniwersytetu. Serija istoryczna" 2014, z. 50, s. 26.

${ }^{24}$ J. Maternicki, Miejsce i rola..., s. 279.

${ }^{25}$ I d e m, Historia i życie narodu..., s. 86.

${ }^{26}$ L. Za s zkilniak, Istorija Ukraijny u Lwiws'komu uniwersyteti $w$ XIX stolitti, [w:] Istorija ta istoryky..., s. 107.

${ }_{27}$ J. Maternicki, Miejsce irola..., s. 275-279; L. Łazurko, Spiwpraca..., s. 189.

${ }^{28} \mathrm{~J}$. Maternicki, Mity historyczne, ich geneza, struktura i funkcje społeczne, [w:] Metodologiczne problemy badań nad dziejami myśli historycznej. Materiały konferencji naukowej $w$ Krynicy w 1989 r., red. J. Maternicki, Warszawa 1990, s. 70; Istoryczni obrazy „susidiw” na ukraijns'ko-polsko-biłorus'komu prikordonni: mify - studiji-pam'jat', red. W.W. Masnenko, Czerkasy 2018, s. 26. 
Bardzo często badacze ukraińscy przytaczają poglądy J. Maternickiego w celu potwierdzenia poprawności własnych twierdzeń. Przykładowo W. Telwak wielokrotnie przytacza jego stwierdzenie dotyczace znaczenia „całościowego opracowania twórczości i idei Michała Hruszewskiego" dla historii historiografii polskiej29. Podczas analizy oceny myśli Jerzego Topolskiego dokonanej przez J. Maternickiego, Darina Buhajowa przytacza takie wyróżnione przez rzeszowskiego profesora perspektywy rozwoju metodologii wiedzy socjohumanistycznej: ontologiczne („wizja świata i człowieka”), metodologiczne (,ideał nauki”, „podstawy metodologiczne”) i aksjologiczne ${ }^{30}$. Zdarza się jednak, że ukraińscy badacze nie zgadzaja się $z$ twierdzeniami J. Maternickiego. Eugeniusz Sinkiewicz twierdzi na przykład, że w odniesieniu do szkół średnich krakowska szkoła historyczna niczego konkretnego nie zrobiła ${ }^{31}$.

Wyniki badań J. Maternickiego maja wyjątkowe znaczenie nie tylko dla rozwoju historiografii polskiej. Jego dokonania zwracaja także uwage uczonych zagranicznych. Dotyczy to w pierwszym rzędzie badaczy $z$ uczelni zachodnioukraińskich.

\section{Bibliografia}

\section{Opracowania}

Arkusza O., Mydryj M., Istoryczni doslidżennja w intelektualnych ta politycznych kontekstach pidawstrijs'koji Hałyczyny, „Wisnyk Lwiws'koho uniwersytetu. Serija istoryczna" 2014, z. 50, s. 19-41.

Bohdaszyna O.N., Pozitiwizm $w$ istoriczeskoj naukie na Ukrainie (60-e gg. XIX - 20-e gg. XXww.), Charkiw 2013.

${ }^{29} \mathrm{~J}$. Mate rnicki, Polskie badania nad lwowskim środowiskiem historycznym w XIX i XX wieku, [w:] Historia $i$ historycy..., s. 122; W. Telwak, [Rec. na kn.:] Łukasz Adamski, Nacjonalista postępowy. Mychajło Hruszewski i jego poglady na Polske i Polaków, Warszawa: Wydawnictwo Naukowe PWN, 2011, 369 s., „Ukraijns'kyj archeohraficznyj szczoricznyk" 2012, t. XVI-XVII, s. 649; W.P. Telwak, W.W. Telwak, Suczasna polska ta rosijs'ka Hruszews'kiana: sproba istoriohraficznoho porienjannja, „Wisnyk Czerkas'koho uniwersytetu, Ser.: Istoryczni nauki” 2009, z. 160-161, s. 80.

${ }^{30}$ J. Maternicki, Wspomnienie o Jerzym Topolskim (1928-1998), „Przegląd Humanistyczny” 1999, nr 5, s. 99; D.A. Bu haj ow a, Metodołogiczna spadszczyna Jeży Topols'koho, Zbirnyk naukowych prac'. Ser.: Istorija ta heohrafiija, Charkiw 2013, nr 47, s. 184.

${ }^{31}$ J. Maternicki, Dydaktyka historii $w$ Polsce 1773-1918, Warszawa 1978, s. 10; E. Sinkiewicz, Michat Bobrzyn'skyj: suspilno-polityczna dijalnist', „Istorycznyj archiw" 2010, z. 5, s. 61. 
Buhajowa D.A., Metodołogiczna spadszczyna Jeży Topolskoho, Zbirnik naukowych prac'. Ser.: Istorija ta heohrafiija, Charkiw 2013, nr 47, s. 181-185.

Galicja 1772-1918. Problemy metodologiczne, stan i potrzeby badań, t. I-III, red. A. Kawalec, W. Wierzbieniec, L. Zaszkilniak, wstęp J. Maternicki, Rzeszów 2011.

Historia, mentalność, tożsamość: Rosja i Europa Zachodnia w polskiej i ukraiñskiej historiografii XIX i XX wieku, red. E. Koko, M. Nowak, L. Zaszkilniaka, Gdańsk-Sopot 2013.

Historia - mentalność - tożsamość. Miejsce i rola historii oraz historyków $w \dot{z} y c i u$ narodu polskiego i ukraińskiego w XIX i XX wieku, red. J. Pisulińska, P. Sierżęga, L. Zaszkilniak, wstęp J. Maternicki, Rzeszów 2008.

Historia - mentalność - tożsamość: studia z historii, historii historiografii i metodologii historii, red. K. Polasik-Wrzosek, W. Wrzosek, L. Zaszkilniak, Poznań 2010.

Istorija - mentalnist' - identicznist', t. IV (Istoryczna pam'jat' ukraijnnciw i poljakiw $u$ period formuwannja istorycznoji swidimosti $w$ XIX - perszij połowyni XX stolittja), red. L. Zaszkilniak, J. Pisulińska, P. Sierżęga, Lwiw 2011.

Istoryczni obrazy „susidiw” na ukraijns'ko-polsko-biłorus'komu prikordonni: mify - studiji-pam'jat', red. W.W. Masnenko, Czerkasy 2018.

Łazurko L., Istorija $i \dot{z} y t t j a ~ n a r o d u ~ w$ wiziji Jeży Maternickoho, „Dorohobyc'kyj krajeznawczyj zbirnyk" 2011, z. 14-15, s. 634-644.

Łazurko L., Kwestie metodologiczne na łamach "Kwartalnika Historycznego" (do 1939 r.), „Klio Polska. Studia i Materiały z Dziejów Historiografii Polskiej” 2016, t. VIII, s. 25-36.

Łazurko L., Spiwpracja redakciji czasopysu „Kwartalnik Historyczny” z Lwiws'kym uniwersytetom (1887-1914 rr.), [w:] Istorija ta istoryky u Lwiws'komu uniwersyteti: tradycii ta suczasnist'. Do 75-littja stworennja istorycznoho fakultetu, red. L. Zaszkilniak, P. Serżenga, Lwiw 2015, s. 185-192.

Maternicki J., Adam Szelagowski i jego poglady na historie, „Przegląd Humanistyczny" 1989, nr 11, s. 123-153.

Maternicki J., Adam Szelagowski i jego poglady na historie, „Przegląd Humanistyczny" 1989, nr 12, s. 105-137.

Maternicki J., Adam Szelagowski wobec historii socjologicznej, [w:] Wielokulturowe środowisko historyczne Lwowa $w$ XX i XIX w., t. IV, red. J. Maternicki, L. Zaszkilniak, Lwów-Rzeszów 2006, s. 178-198.

Maternicki J., Dydaktyka historii w Polsce 1773-1918, Warszawa 1978.

Maternicki J., Historia jako dialog. Studia i szkice historiograficzne, Rzeszów 1996.

Maternicki J., Idee i postawy. Historia $i$ historycy polscy 1914-1918. Studium historiograficzne, Warszawa 1975.

Maternicki J., Michał Bobrzyński wobec tzw. idei jagiellońskiej. Ewolucja pogladów i jej uwarunkowania, „Przegląd Humanistyczny” 1977, nr 12, s. 131-142.

Maternicki J., Mity historyczne, ich geneza, struktura i funkcje społeczne, [w:] Metodologiczne problemy badań nad dziejami myśli historycznej. Materiały konferencji naukowej w Krynicy w 1989 r., red. J. Maternicki, Warszawa 1990, s. 66-80. 
Maternicki J., Polska refleksja teoretyczna i metodologiczna $w$ dziedzinie historii w okresie modernizmu i neoromantyzmu. Metamorfozy myśli pozytywistycznej, [w:] J. Maternicki, Historiografia i kultura historyczna: studia i szkice, t. I, Warszawa 1990, s. 220-272.

Maternicki J., Polskie środowisko historyczne w latach 1900-1918, „Przeglad Humanistyczny" 1980, nr 4-5, s. 11-29.

Maternicki J., "Rewolucje” i przełomy w historiografii polskiej XIX i XX w. Próba analizy czynników sprawczych, [w:] J. Maternicki, Kultura historyczna dawna i współczesna: Studia i szkice, Warszawa 1979, s. 11-31.

Maternicki J., Trudna profesura. Adam Szelagowski wśród przeciwieństw i niepowodzen życiowych we Lwowie w latach 1909-1939, [w:] J. Maternicki, Historia i historycy: Studia i szkice historiograficzne, Rzeszów 2005, s. 174-204.

Maternicki J., Wspomnienie o Jerzym Topolskim (1928-1998), „Przegląd Humanistyczny" 1999, nr 5, s. 95-102.

Pestrykowa O., Doba Chmielnyczczyny w interpretacii polskoho istoryka Ludwika Kubali, „Hrani” 2018, nr 2 (21) s. 83-91.

Ruda O., Berestejska unija u doslidżennjach lwiws'kich istorykiw (1890-1914), „Problemy słow’janoznawstwa” 2008, z. 57, s. 63-72.

Sinkiewicz E., Zmina paradygmy polskoji istoriografiji $w$ umowach widrodżennja derżawnosti (1918-1939), „Naukowi praci Czornomor. derżw. un-t im. P. Mohyły", Ser.: istorija 2011, t. CLIV, z. 142, s. 87-91.

Sinkiewicz E.H., Kozac'kyj i jagiełłons'kyj mify w polskoj ta ukraijnskij istoriografiji, „Naukowi praci Mikołajiws'koho derżawnoho humanitarnoho uniwersytetu im. Petra Mohyły kompleksu Kijewo-Mohyljans'ka akademija”, Ser.: Istoryczni nauki 2008, t. XCVI, z. 83, s. 240-242.

Sinkiewicz E.H., Michał Bobrzyn'skyj: suspilno-polityczna dijalnist', „Istorycznyj archiw" 2010, z. 5, s. 60-63.

Telwak W., [Rec. na kn.:] Łukasz Adamski, Nacjonalista postepowy. Mychajło Hruszewski i jego poglady na Polskę i Polaków, Warszawa: Wydawnictwo Naukowe PWN, 2011, 369 s., „Ukraijns'kyj archeohraficznyj szczoricznyk” 2012, t. XVI-XVII, s. 637-649.

Telwak W.P., Telwak W.W., Suczasna polska ta rosijs'ka Hruszews'kiana: sproba istoriohraficznoho porienjannja, „Wisnyk Czerkas'koho uniwersytetu, Ser.: Istoryczni nauki” 2009, z. 160-161, s. 77-86.

Telwak W.W., Pedycz W.P., III Miżnarodna konferencija „Istorija - mentalnist' - identicznist”, „Ukraijns'kyj istorycznyj źurnał” 2009, nr 6, s. 225-226.

Wielokulturowe środowisko historyczne Lwowa w XIX i XX w., red. J. Maternicki, L. Zaszkilniak, t. I-V, Rzeszów 2004-2007.

Zaszkilniak L., Istorija Ukraijny u Lwiws'komu uniwersyteti $w$ XIX stolitti, [w:] Istorija ta istoryky u Lwiws'komu uniwersyteti: tradycii ta suczasnist'. Do 75-littja stworennja istorycznoho fakultetu, red. L. Zaszkilniak, P. Serżenga, Lwiw 2015, s. 91-109.

Zaszkilniak L., Spiwrobitnyjstwo ukraijns'kich i polskich istorykiw na suczasnomu etapi: istoriohraficzni aspekty, „Naukowy zapysky Nacjonalnoho uniwersytetu „Ostroz'ka akademija. Istoryczni nauki” 2008, z. 10, s. 366-388. 
Zaszkilniak L.O., II Miżnarodna konferencija „Istorija - mentalnist' - identycznist”, „Ukraijns'kyj istorycznyj źurnał” 2004, nr 1, s. 232-233.

Zaszkilniak L.O., Kril M.M., Tretja miżnarodna naukowa konferencija „Bahatokulturne istoryczne seredowiszcze Lwiwa u XIX-XX st., „Ukraijns'kyj istorycznyj źurnał" 2005, nr 2, s. 224-226.

Zaszkilniak L.O., Ruda O.W., IV Miżnarodna naukowa konferencija „Bahatokulturne istoryczne seredowiszcze Lwiwa w XIX - perszij połowyni XX st.”, „Ukraijns'kyj istorycznyj źurnał" 2006, nr 1, s. 231-233.

Złota ksiega historiografii lwowskiej XIX i XX wieku, red. J. Maternicki, Rzeszów 2007.

Złota ksiega historiografii lwowskiej XIX $i$ XX wieku, t. II, red. J. Maternicki, P. Sierżęga, L. Zaszkilniaka, Rzeszów 2014.

Olena Bohdaszyna

H.S. Skovoroda Kharkiv National Pedagogical University

\section{The influence of Jerzy Maternicki's thought on contemporary Ukrainian historiography}

\footnotetext{
$\mathrm{T}$ he article presents the influence of Jerzy Maternicki's works on the development of contemporary Ukrainian historiography. The Author has analyzed a number of works by Ukrainian historians who refer in their research to his studies. She showed a significant influence of Jerzy Maternicki on strengthening Polish-Ukrainian scientific contacts.
}

Keywords: Jerzy Maternicki, Polish historiography, contemporary Ukrainian historiography, University of Warsaw, University of Rzeszów. 